\title{
Psychiatric and cognitive comorbidities of persistent post-traumatic headache attributed to mild traumatic brain injury
}

\author{
Håkan Ashina ${ }^{1,2}$ (D) Haidar Muhsen Al-Khazali ${ }^{1}$, Afrim Iljazi ${ }^{1}$, Sait Ashina ${ }^{3,4,5,6}$, Faisal Mohammad Amin ${ }^{1}$, \\ Richard B. Lipton ${ }^{7,8}$ and Henrik Winther Schytz ${ }^{1 *}$
}

\begin{abstract}
Objective: To investigate the association of psychiatric and cognitive comorbidities with persistent post-traumatic headache (PTH) attributed to mild traumatic brain injury (TBI).

Methods: A total of 100 patients with persistent PTH attributed to mild TBI and 100 age- and gender-matched healthy controls free of mild TBI were enrolled between July 2018 and June 2019. Quality of sleep was evaluated using the Pittsburgh Sleep Quality Index, while symptoms of anxiety and depression were assessed using the Hospital Anxiety and Depression Scale. Cognitive impairment was evaluated using the Montreal Cognitive Assessment questionnaire, while post-traumatic stress disorder (PTSD) was assessed using the Harvard Trauma Questionnaire.

Results: In 100 patients with persistent PTH, 85\% reported poor quality sleep, compared with $42 \%$ of healthy controls $(P<0.01)$. The relative frequency of probable to high risk of anxiety was $52 \%$ in the persistent PTH group vs. $8 \%$ in healthy controls $(P<0.01)$, while the relative frequency of probable to high risk of depression was $42 \%$ in the persistent PTH group vs. $2 \%$ in healthy controls $(P<0.01)$. Furthermore, $27 \%$ of the patients with persistent PTH had mild cognitive impairment while $10 \%$ had probable PTSD.

Conclusions: Poor quality of sleep as well as symptoms suggestive of anxiety and depression were more common in patients with persistent PTH than healthy controls. Clinicians should screen patients with persistent PTH for these comorbidities and develop treatment plans that account for their presence.
\end{abstract}

Keywords: Sleep, Anxiety, Depression, Cognitive impairment, Post-traumatic stress disorder

\section{Introduction}

Headache is a common sequela of mild traumatic brain injury (TBI), [1-3], as well as a frequent cause of chronic daily headache in the general population [4]. Few efforts have been made to assess the broader clinical picture of post-traumatic headache (PTH), [5-7]. The diagnosis of

\footnotetext{
* Correspondence: henrik.winther.schytz.01@regionh.dk

'Department of Neurology, Danish Headache Center, Rigshospitalet Glostrup, Faculty of Health and Medical Sciences, University of Copenhagen, Valdemar Hansen Vej 5, DK-2600 Glostrup, Denmark

Full list of author information is available at the end of the article
}

PTH is based on clinical criteria provided by the International Classification of Headache Disorders, 3rd edition (ICHD-3), and termed headache attributed to traumatic injury to the head [8]. Herein, PTH is characterized as either acute PTH, which develops within 7 days of the TBI and then remits within 3 months of onset, or persistent $\mathrm{PTH}$, which persists beyond the 3 month-mark [8]. PTH is furthermore classified according to the severity of attributable TBI, being either mild or moderate to severe [8].

(c) The Author(s). 2021 Open Access This article is licensed under a Creative Commons Attribution 4.0 International License, which permits use, sharing, adaptation, distribution and reproduction in any medium or format, as long as you give appropriate credit to the original author(s) and the source, provide a link to the Creative Commons licence, and indicate if changes were made. The images or other third party material in this article are included in the article's Creative Commons licence, unless indicated otherwise in a credit line to the material. If material is not included in the article's Creative Commons licence and your intended use is not permitted by statutory regulation or exceeds the permitted use, you will need to obtain permission directly from the copyright holder. To view a copy of this licence, visit http://creativecommons.org/licenses/by/4.0/ The Creative Commons Public Domain Dedication waiver (http://creativecommons.org/publicdomain/zero/1.0/) applies to the data made available in this article, unless otherwise stated in a credit line to the data. 
A key observation from clinic-based studies is that persistent PTH most often resembles a migraine-like headache phenotype, although some patients may report a 'pure' tension-type-like headache (TTH-like) phenotype $[2,5,9]$. Although the headache features of persistent PTH have been documented in multiple studies [2, $5,6,9]$, there is a scarcity of literature on associated comorbidities [7]. These include sleep disturbances, anxiety, depression, cognitive impairment, and posttraumatic stress disorder (PTSD) [7]. From a clinical standpoint, it is important to assess comorbidities as they are likely to have an important role in the longterm management and well-being of the patient. The presence of comorbidities might also affect the choice of therapy and, thus, facilitate more informed treatment approaches.

In this cross-sectional study, we assessed quality of sleep, anxiety, depression, cognitive impairment, and PTSD as comorbidities of persistent PTH. Age- and gender-matched healthy controls were used to compare rates of poor quality of sleep, anxiety, and depression. We hypothesized that symptoms suggestive of these comorbidities would be more frequent in patients with persistent PTH, compared with healthy controls.

\section{Methods}

\section{Study population}

We enrolled patients with persistent PTH attributed to mild TBI. Patients were recruited from the outpatient clinic of the Danish Headache Center, the Danish postconcussion syndrome support group website (hjernerystelsesforeningen.dk), and from neurological departments and rehabilitation centers in the Capital Region of Denmark. Healthy non-headache controls were recruited through the Danish research subject website (forsøgsperson.dk) and posters placed at various public institutions in the Capital Region of Denmark. A trained locum doctor (HMA) was responsible for the initial screening of study eligibility by phone.

This article is part of a larger parental study that was approved by the Regional Health Research Ethics Committee of the Capital Region of Denmark (H-18011477), [5]. All participants gave written consent after receiving detailed oral and written information. The study was conducted at the Danish Headache Center in accordance with the Declaration of Helsinki [10], with later revisions. The study was also approved by the Danish Data Protection Agency.

\section{Inclusion and exclusion criteria}

The diagnosis of persistent PTH attributed to mild TBI was established by a trained locum doctor (AI) using a semi-structured interview and made in accordance with the ICHD-3 criteria for persistent headache attributed to mild traumatic injury to the head [8]. Table 1 sets out the ICHD-3 criteria for mild traumatic injury to the head. Other inclusion criteria for individuals with persistent PTH were: 1) mild TBI to have occurred at least 12 months prior to study participation and 2) age between 18 and 65 years. Exclusion criteria were 1) any history of primary headache disorder (except infrequent TTH), 2) any history of whiplash injury or more than one TBI, 3) pregnant or nursing women, 4) cardiovascular or cerebrovascular disease, 5) pre-trauma psychiatric disorder (unless well-regulated), and 6) medicationoveruse headache. To ensure eligibility for inclusion, medical records were reviewed to cross-check for any formal medical or psychiatric diagnosis. Moreover, we required no intake of analgesics within $24 \mathrm{~h}$ of study participation because study participants were scheduled for functional magnetic resonance imaging and blood sampling as part of the larger parental study. Some of the data from the larger parental study have been published elsewhere $[5,11,12]$.

Inclusion criteria for healthy controls were 1) age between 18 and 65 years, 2) no history of known head trauma or whiplash injury, 3) no history of primary headache disorder (except infrequent episodic TTH), 4) no first-degree relatives with primary headache disorder, 5) no daily intake of medicine other than oral contraceptives, 6) no history of neurological or psychological

Table 1 Diagnostic criteria for mild traumatic injury to the head. ${ }^{\text {a }}$

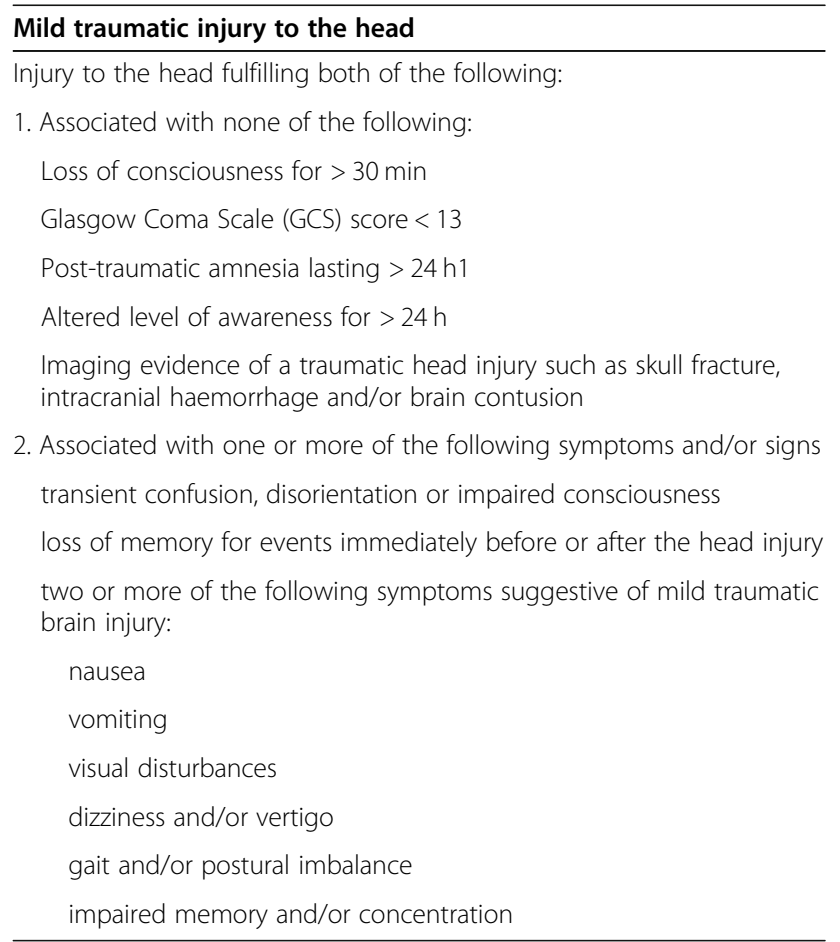

${ }^{a}$ Diagnostic criteria are from the International Classification of Headache Disorders, 3rd edition (ICHD-3), [8] 
disorders, 7) no history of structural heart disease. An in-person structured interview was performed by a trained locum doctor (AI) to determine study eligibility. Medical records were reviewed to cross-check for any formal medical or psychiatric diagnosis.

\section{Measures}

An in-person semi-structured interview was used to record data on demographics, medical history, and full clinical course. The assignment of headache phenotypes was based on review of clinical features in patients with persistent PTH and without consideration of the ICHD-3 criterion for primary headache disorders, which states "not better accounted for by another ICHD-3 diagnosis". As study inclusion was based on a diagnosis of persistent PTH attributed mild TBI, we used terms such as migraine-like and TTH-like to describe assigned headache phenotypes. The case definitions, that were used to classify migraine-like and TTH-like days, have been published elsewhere [13].

\section{Pittsburg sleep quality index}

The Pittsburg Sleep Quality Index (PSQ-I) is a 19-item self-report instrument that comprises 7 components used to assess quality of sleep [14]. Each component is scored on a scale of 0 to 3 , which is then used to calculate a global score of 0 to 21 . Poor quality of sleep is defined as global scores of 5 or higher. The appraisal period is the past 30 days.

\section{Hospital anxiety and depression scale}

The Hospital Anxiety and Depression Scale (HADS) is a 14-item self-report instrument used to screen for anxiety and depression separately [15]. The range of the scale is 0 to 21 , with scores of 8 to 10 being indicative of a probable risk of anxiety or depression, whereas scores of 11 to 21 indicate a high risk of anxiety or depression. The appraisal period is the past 7 days.

\section{Montreal cognitive assessment}

The Montreal Cognitive Assessment (MoCA) questionnaire is a 30-item instrument used to screen for cognitive impairment [16]. The range of the scale is 0 to 30 , and scores of 26 or less are indicative of cognitive impairment. The degree of cognitive impairment is denoted as mild if scores are between 18 to 25 . The MoCA questionnaire was only administered to patients with persistent $\mathrm{PTH}$.

\section{Harvard trauma questionnaire}

The Harvard Trauma Questionnaire (HTQ) is a 16-item instrument used to screen for PTSD [17]. Each item is rated on a four-point Likert scale, and total mean scores of 2.5 or higher are indicative of probable PTSD. The appraisal period is the past 7 days. The HTQ questionnaire was only administered to patients with persistent PTH.

\section{Statistical analysis}

Descriptive statistics were used to summarize baseline characteristics. Continuous variable were reported as means and standard deviations (SDs), whereas categorical variables were summarized as proportions and/or percentages. Comparisons were performed using a $t$ test for continuous variables and a $\chi^{2}$ test for categorical variables. For analyses of correlation, we used the Spearman rank correlation coefficient $\left(r_{s}\right)$. All statistical analyses were conducted using IBM SPSS Statistics for Windows, Version 25.0, Armonk, NY, USA.

\section{Results}

A total of 100 patients with persistent PTH and 100 ageand gender-matched healthy controls were enrolled between July 2018 and June 2019. Of 100 participants in both groups, 83 were females and 17 were males. The mean age (SD) was 36.0 (11.6) years in patients with persistent PTH and 35.8 (11.3) years in healthy controls. Furthermore, the mean BMI (SD) was $24.5(4.1) \mathrm{kg} / \mathrm{m}^{2}$ in patients with persistent PTH and $24.3(3.7) \mathrm{kg} / \mathrm{m}^{2}$ in healthy controls. A more detailed summary has been published elsewhere [5] and is also presented in Tables 2, 3 and 4. In brief, patients with persistent PTH had a mean (SD) headache frequency of 25.4 (7.1) days per month. The most common headache phenotypes were chronic migraine-like $(n=61)$ followed by combined episodic migraine-like and episodic/chronic TTH-like $(n=$ 29), 'pure' chronic TTH-like $(n=9)$, and episodic migraine-like headache $(n=1)$, (Table 3$)$.

Table 2 Summary Characteristics

\begin{tabular}{lll}
\hline Variable & Persistent PTH $(\boldsymbol{n}=\mathbf{1 0 0})$ & Healthy Controls $(\boldsymbol{n}=\mathbf{1 0 0})$ \\
\hline Age, mean (SD), y & $36.0(11.7)$ & $35.8(11.3)$ \\
Male/Female, \% & $17 / 83$ & $18 / 82$ \\
Height, mean (SD), cm & $171.3(8.2)$ & $170.9(8.7)$ \\
Weight, mean (SD), $\mathrm{kg}$ & $72.1(14.4)$ & $71.2(14.2)$ \\
Body Mass Index, mean (SD), $\mathrm{kg} / \mathrm{m}^{2}$ & $24.5(4.1)$ & $24.3(3.7)$ \\
\hline
\end{tabular}


Table 3 Characteristics of Patients with Persistent Post-Traumatic Headache

Variable

Persistent PTH $(n=100)$

Age, mean (SD), y

$36.0(11.7)$

Male/Female, \%

Height, mean (SD), cm

$171.3(8.2)$

Weight, mean (SD), kg

$72.1(14.4)$

Body Mass Index, mean (SD), $\mathrm{kg} / \mathrm{m}^{2}$

Current Employment Status, \%

Full-time employed

Part-time employed

Unemployed

\section{Education}

Years of education, mean (SD), y

No education besides completion of secondary school or high school, \%

Skilled labor, \%

Bachelor's degree, \%

Higher education, \%

Injury Cause, \%

Fall

Motor vehicle collision

Sports-related injury

Violence/assault

Other unintentional injury

Localization of Mild TBI, \%

Frontal

Temporal

Parietal

Occipital

Mild TBI associated with, \%

Transient confusion, disorientation, or impaired consciousness

Loss of memory for events immediately before or after the head injury

Nausea

Vomiting

Visual disturbances

Dizziness and/or vertigo

Gait and/or postural imbalance

Impaired memory and/or concentration

Months with Headache attributed to Mild TBI, mean (SD), months

\section{Headache Phenotypes, \%}

Chronic migraine-like

Episodic migraine-like

Episodic migraine-like combined with chronic TTH-like

Episodic migraine-like combined with frequent TTH-like 
Table 3 Characteristics of Patients with Persistent Post-Traumatic Headache (Continued)

\begin{tabular}{ll}
\hline Variable & Persistent PTH $(\boldsymbol{n}=\mathbf{1 0 0})$ \\
\hline Excellent & 2 \\
Great & 12 \\
Good & 34 \\
Rather poor & 38 \\
Poor & 14 \\
Medico-Legal Issues / Litigation, \% & 31 \\
Ongoing litigation & 44 \\
Ended litigation & $1(2.3 \%)$ \\
Improvement in headache following end of litigation, No. of subjects (\%) & 23 \\
Pre-Trauma Psychiatric History, \% & 12 \\
Anxiety disorders & 14 \\
Major depressive disorder & 4 \\
Eating disorders & 11 \\
Pre-Trauma Chronic Pain Conditions ${ }^{\text {a }} \%$ & 12 \\
Neck pain & 1 \\
Low back pain & 0 \\
Neuropathic pain & 3 \\
Other chronic pain conditions & 1 \\
\hline
\end{tabular}

${ }^{a}$ chronic pain was defined as persistent or recurrent pain that lasted longer than 3 months

\section{Associated comorbidities}

Tables 5 and 6 summarize outcome rates for poor quality of sleep, anxiety, depression, mild cognitive impairment, and PTSD. In 100 patients with persistent PTH, $85 \%$ had poor quality of sleep, $52 \%$ had at least probable risk of anxiety, $42 \%$ had at least probable risk of depression, $27 \%$ had mild cognitive impairment, and 10\% had probable PTSD. Compared with healthy controls, patients with persistent PTH had a higher relative frequency of poor quality of sleep ( $85 \%$ vs. $42 \%, P<0.01)$, anxiety $(52 \%$ vs. $8 \%, P<0.01)$, and depression $(42 \%$ vs. $2 \%, P<0.01)$. Another observation was that $28 \%$ of patients with persistent PTH had poor quality of sleep, as well as at least probable risk of both anxiety and depression.

In 91 patients with a migraine-like phenotype, 88\% had poor quality of sleep, $56 \%$ had at least probable risk of anxiety, and $43 \%$ had at least probable risk of depression. The corresponding figures for 61 patients with a chronic migraine-like phenotype were 93\%, 46\%, and 56\% (Table 6).

\section{Correlations}

Global PSQ-I scores correlated with HADS anxiety scores $(r=0.31 ; P<0.01)$ and HADS depression scores $(r=0.37 ; P<0.01)$, whereas no significant correlation was found with monthly headache days $(r=0.19 ; P=$ $0.18)$, monthly migraine-like days $(r=0.19 ; P=0.08)$, or months with headache attributed to mild TBI $(r=0.08$; $P=0.42$ ). HADS anxiety scores correlated with HADS depression scores $(r=0.56 ; P<0.01)$, whilst no relationship was observed with monthly headache days $(r=-$ $0.02 ; P=0.86)$, monthly migraine days $(r=0.02 ; P=$ $0.83)$, or months with headache attributed to mild TBI $(r=-0.13 ; P=0.19)$. HADS depression scores did not correlate with monthly headache days $(r=0.02 ; P=$ $0.84)$, monthly migraine days $(r=0.15 ; P=0.15)$, or months with headache attributed to mild TBI $(r=-12$; $P=0.23)$.

\section{Discussion}

This study presents data on comorbidities in 100 patients with persistent PTH and 100 age- and gendermatched healthy controls. When comparing the two groups, poor quality of sleep ( $85 \%$ vs. $42 \%)$, at least probable risk of anxiety ( $52 \%$ vs. $8 \%$ ), and at least probable risk of depression ( $42 \%$ vs. $2 \%$ ) were more frequently observed in patients with persistent PTH. In addition, mild cognitive impairment was present in $27 \%$ of patients with persistent PTH, whilst probable PTSD was found in $10 \%$. These findings underscore that patients with persistent PTH often experience symptoms suggestive of psychiatric and cognitive comorbidities. An initial screening for comorbid conditions should be used in clinical practice to facilitate treatment schemes that are more carefully matched to patients. This, in turn, 
Table 4 Headache Characteristics of the Study Population

\begin{tabular}{|c|c|c|c|c|}
\hline Variable & $\begin{array}{l}\text { Persistent PTH } \\
(n=100)\end{array}$ & $\begin{array}{l}\text { Chronic Migraine- } \\
\text { Like }(n=61)\end{array}$ & $\begin{array}{l}\text { Episodic Migraine-Like combined with } \\
\text { TTH-like }(n=29)\end{array}$ & $\begin{array}{l}\text { Chronic TTH- } \\
\text { like }(n=9)\end{array}$ \\
\hline \multicolumn{5}{|l|}{ Headache Frequency, mean (SD) } \\
\hline Yearly headache days & 307.9 (86.9) & $299.3(88.3)$ & $318.5(83.0)$ & $358.1(12.8)$ \\
\hline Monthly headache days & $25.4(7.1)$ & $24.6(7.5)$ & $26.2(6.8)$ & $29.7(0.7)$ \\
\hline \multicolumn{5}{|l|}{ Headache Intensity ${ }^{\mathrm{a}}, \%$} \\
\hline Mild & 5 & 0 & 0 & 56 \\
\hline Moderate & 80 & 82 & 86 & 44 \\
\hline Severe & 15 & 18 & 14 & 0 \\
\hline \multicolumn{5}{|l|}{ Headache Localization, \% } \\
\hline Bilateral & 64 & 69 & 62 & 56 \\
\hline Unilateral & 36 & 31 & 38 & 44 \\
\hline Left sided & 18 & 16 & 17 & 22 \\
\hline Right sided & 17 & 15 & 21 & 22 \\
\hline Frontal & 70 & 70 & 72 & 67 \\
\hline Temporal & 50 & 51 & 41 & 67 \\
\hline Parietal & 35 & 39 & 21 & 44 \\
\hline Occipital & 35 & 41 & 24 & 33 \\
\hline \multicolumn{5}{|l|}{ Headache Quality, \% } \\
\hline Throbbing & 18 & 23 & 14 & 0 \\
\hline Pressing & 32 & 21 & 31 & 100 \\
\hline Stabbing & 3 & 2 & 7 & 0 \\
\hline Combined (throbbing and pressing) & 45 & 51 & 48 & 0 \\
\hline Other headache quality & 2 & 3 & 0 & 0 \\
\hline $\begin{array}{l}\text { Family History of Primary Headache } \\
\text { Disorders }{ }^{\mathbf{b}}, \%\end{array}$ & 28 & 31 & 21 & 22 \\
\hline Continuous Photophobiac', \% & 46 & 69 & 45 & 44 \\
\hline Continuous Phonophobia ${ }^{d}, \%$ & 60 & 61 & 28 & 0 \\
\hline Neck Pain, \% & 78 & 82 & 79 & 44 \\
\hline $\begin{array}{l}>180 \text { days with neck pain within the } \\
\text { past } 12 \text { months, } \%\end{array}$ & 55 & 78 & 52 & 33 \\
\hline Low Back Pain, \% & 37 & 38 & 45 & 11 \\
\hline $\begin{array}{l}>180 \text { days with neck pain within the } \\
\text { past } 12 \text { months, } \%\end{array}$ & 24 & 26 & 23 & 0 \\
\hline \multicolumn{5}{|l|}{ Allodynia $^{e}$} \\
\hline None, $\%$ & 54 & 44 & 66 & 78 \\
\hline Mild Allodynia, \% & 23 & 25 & 21 & 22 \\
\hline Moderate Allodynia, \% & 17 & 23 & 10 & 0 \\
\hline Severe Allodynia, \% & 6 & 8 & 3 & 0 \\
\hline
\end{tabular}

${ }^{a}$ mild headache intensity = does not impair ability to work and/or other activities. Moderate headache intensity=impairs but does not prevent ability to work and/ or other activities. Severe headache intensity = prevents ability to work and/or other activities

${ }^{\mathrm{b}}$ positive family history of primary headache disorders $=1$ st degree relative with any primary headache disorder other than infrequent tension-type headache

c continuous photophobia = continuously ongoing - daily - symptoms of photophobia

${ }^{d}$ continuous phonophobia = continuously ongoing - daily - symptoms of phonophobia

' cutaneous allodynia scores were assessed using the 12-item Allodynia Symptom Checklist (ASC-12) and defined as follows: none (scores 0-2), mild [3-5],

moderate [6-8], and severe $(\geq 9)$ 
Table 5 Comorbidities of the Study Population

\begin{tabular}{|c|c|c|c|}
\hline Comorbidities & Persistent PTH $(n=100)$ & Healthy Controls $(n=100)$ & $P$ value \\
\hline \multicolumn{4}{|l|}{ Subjective Sleep Quality } \\
\hline Poor Sleep Quality ${ }^{a}$, No. & 85 & 42 & $<0.01$ \\
\hline Anxiety & & & $<0.01$ \\
\hline Probable or High Risk of Anxiety, No. & 52 & 8 & \\
\hline Probable Risk of Anxiety, \% & 19 & 8 & \\
\hline High Risk of Anxiety, \% & 33 & 0 & \\
\hline Depression & & & $<0.01$ \\
\hline Probable or High Risk of Depression, No. & 42 & 2 & \\
\hline Probable Risk of Depression, $\%$ & 30 & 2 & \\
\hline High Risk of Depression, \% & 12 & 0 & \\
\hline Mild Cognitive Impairment, No. & 27 & N/A & N/A \\
\hline Post-Traumatic Stress Disorder, No. & 10 & N/A & N/A \\
\hline
\end{tabular}

would be a much needed move away from the conventional one-size-fits-all approach.

Our finding of poor quality of sleep in most patients with persistent $\mathrm{PTH}$ is in accord with previous observations [7, 18]. A recent clinic-based study found that $26 \%$ of patients with persistent PTH had a severe degree of insomnia, whilst $40 \%$ had a moderate degree of insomnia [18]. The same study also found that insomnia was more frequent in patients with persistent $\mathrm{PTH}$, compared with patients with migraine [18]. This is an interesting observation because a recent web-based survey reported that insomnia is more common in individuals with migraine than non-migraine controls [19]. A meta-analysis has estimated that sleep disturbances are experienced by about $50 \%$ of individuals who sustain a TBI [20], Taken together, it is evident that poor quality of sleep is prevalent in patients with persistent PTH attributed to mild TBI.

Besides poor quality of sleep, we found that anxiety and depression are more frequent in patients with persistent PTH, compared with healthy controls. These associations have several possible explanations. For example, anxiety and depression may be independent risk factors for the development of TBI-related sequelae, such as persistent PTH. Another option is that anxiety and depression are sequelae of TBI that are unrelated to persistent PTH per se. Lastly, they could indeed be linked to persistent PTH. Many studies indicate that that anxiety and depression are common sequela in patients with TBI $[21,22]$. A prospective cohort study found that the relative frequency of anxiety and depression was higher in patients with persistent $\mathrm{PTH}$, compared with those who had sustained a mild TBI but did not report headache [23]. Longitudinal data is required to resolve the timing of $\mathrm{PTH}$, anxiety, depression following mild TBI.

An interesting finding from our study is that mild cognitive impairment was experienced by $27 \%$ of patients with persistent PTH. This is in line with findings from a prospective cohort study of patients with mild TBI [24]. The authors reported that about $60 \%$ of patients, who had sustained a mild TBI, reported at least one cognitive symptom at 6 months and 12 months post-trauma [24]. Furthermore, another study found that cognitive performance at 2 weeks postinjury was lower in patients with mild TBI when compared with healthy controls [25].

Although there are robust data that the risk of PTSD is increased after mild TBI [22, 26, 27], it remains unclear to what extent individuals with persistent PTH are affected by PTSD. Two small clinic-based studies have

Table 6 Comorbidities of the Chronic Migraine-Like Group

\begin{tabular}{|c|c|c|c|}
\hline Comorbidities & $\begin{array}{l}\text { Chronic Migraine-Like } \\
(n=61)\end{array}$ & Other Headache Phenotypes $(n=39)$ & $P$ value \\
\hline \multicolumn{4}{|l|}{ Subjective Sleep Quality } \\
\hline Poor Sleep Quality, \% & 93 & 72 & $<0.05$ \\
\hline \multicolumn{4}{|l|}{ Anxiety } \\
\hline Probable or High Risk of Anxiety, $\%$ & 46 & 54 & 0.35 \\
\hline \multicolumn{4}{|l|}{ Depression } \\
\hline Probable or High Risk of Depression, \% & 56 & 74 & 0.32 \\
\hline
\end{tabular}


found that about $30 \%$ of patients with persistent $\mathrm{PTH}$ have PTSD $[28,29]$. In contrast, we found that $10 \%$ of patients with persistent PTH had probable PTSD. The discordant findings could be due to differences in methodology or the pre-injury characteristics of the study populations. Nonetheless, it should be noted that some experimental data does support a possible bidirectional relation between PTH and PTSD, possibly attributed to dysfunction in pain modulatory circuits [30].

\section{Limitations}

Several limitations should be noted before considering the implications of our findings. First, we excluded individuals with a personal history of primary headache disorder (except infrequent episodic TTH) from inclusion in the control group [8]. This might have affected the observed relative frequencies of poor quality of sleep, anxiety, and depression. Indeed, there is evidence to suggest an association of migraine and TTH with these comorbidities [19, 31-33]. Another point, that merits emphasis, is the occurrence of pre-trauma psychiatric history in $23 \%$ of patient with persistent $\mathrm{PTH}$, compared with none in the control group. This might yield higher comorbidity scores for patients with persistent PTH. However, it should be mentioned that none of the patients with persistent PTH received treatment for any psychiatric disorder at the time of the mild TBI. Second, we used questionnaires for screening of comorbidities rather than diagnostic instruments. This could result in an over- or underestimation of the caseness prevalence. In addition, we are not able to provide a detailed clinical description of the assessed comorbidities when using screeners. Third, we used a cross-sectional design, which therefore does not allow for causality to be inferred. This study should, therefore, be considered a first step in the investigation of comorbidities associated with persistent PTH. Causation should be ascertained in future prospective cohort studies. Lastly, we recruited patients with persistent PTH who had sought medical care or were involved with patient-support groups. Thus, it is plausible that our study population is skewed towards more adversely affected individuals with persistent PTH.

\section{Conclusions}

Poor quality of sleep, anxiety, and depression are more common in patients with persistent PTH, compared with healthy controls. In addition, some patients with persistent PTH have symptoms suggestive of mild cognitive impairment and PTSD. These findings underscore that patients should be screened for common comorbidities during the initial clinical assessment. Recognition of these might, in turn, affect choice of therapy and highlight the need for more active follow-up. In addition, effective management of comorbidities might be useful in improving treatment outcomes for persistent PTH.

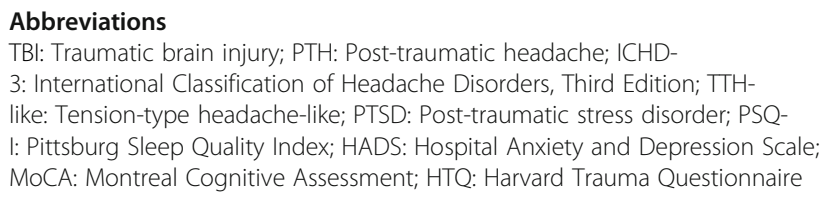

\section{Acknowledgements}

Not applicable.

\section{Authors' contributions}

HA: Study concept and design, acquisition of data, analysis (including statistical analyses) and interpretation, drafting the manuscript. HMA: Acquisition of data and critical revision of the manuscript for important intellectual content. Al: Acquisition of data and critical revision of the manuscript for important intellectual content. SA: Analysis (including statistical analyses) and interpretation, critical revision of the manuscript for important intellectual content. FMA: Critical revision of the manuscript for important intellectual content. RBL: Critical revision of the manuscript for important intellectual content. HWS: Study concept and design, critical revision of the manuscript for important intellectual content, supervision.

\section{Funding}

The authors disclosed receipt of the following financial support for the research, authorship, and/or publication of this Article: The study was supported by a research grant from Rigshospitalet Research Foundation (F23340-02) as well as a research grant from the American Brain Foundation, American Academy of Neurology and the International Headache Society.

\section{Availability of data and materials}

Qualified researchers can request access to patient-level data and related study documents, including the study protocol. Patient-level data will be deidentified and study documents will be redacted to protect the privacy of study participants.

\section{Declarations}

\section{Ethics approval and consent to participate}

Informed written consent was obtained from each patient before conducting any study-related procedures. The study protocol was approved by the relevant ethics committee and institutional review board.

\section{Consent for publication}

Not applicable.

\section{Competing interests}

The authors declared the following potential conflicts of interest with respect to the research, authorship and/or publication of this article: Sait Ashina has received honoraria from Allergan and Teva and consultant fees from Amgen and Allergan. Sait Ashina received honoraria for consulting for Allergan, Amgen, Eli Lilly, Novartis, Promius, Satsuma, Supernus, and Theranica. Faisal Mohammad Amin is a lecturer or scientific advisor for Teva, Eli Lilly, Lundbeck, and Novartis. Messoud Ashina has received personal fees from Alder BioPharmaceuticals, Allergan, Amgen, Eli Lilly, Novartis, and Teva. MA also participated in clinical trials as the principal investigator for Alder, Amgen, electroCore, Novartis, and Teva. Richard B. Lipton serves on the editorial boards of Neurology and Cephalalgia and as senior advisor to Headache; has received research support from the National Institutes of Health $(\mathrm{NIH})$; receives support from the Migraine Research Foundation and the National Headache Foundation; has reviewed for the National Institute on Aging (NIA) and the National Institute of Neurological Disorders and Stroke (NINDS); serves as consultant, advisory board member, or has received honoraria from Alder, Allergan, Amgen, Autonomic Technologies, Avanir, Boston Scientific, Dr. Reddy's, ElectroCore, Eli Lilly, eNeuraTherapeutics, GlaxoSmithKline, Merck, Novartis, Teva, and Vedanta; receives royalties from Wolff's Headache and Informa; holds stock options in eNeura Therapeutics and Biohaven. Henrik Winther Schytz received speaking fees from Novartis and Teva. The other authors declare no conflicts of interest. 


\section{Author details}

'Department of Neurology, Danish Headache Center, Rigshospitalet Glostrup, Faculty of Health and Medical Sciences, University of Copenhagen, Valdemar Hansen Vej 5, DK-2600 Glostrup, Denmark. ${ }^{2}$ Department of

Neurorehabilitation and Traumatic Brain Injury, Rigshospitalet, Copenhagen, Denmark. ${ }^{3}$ Comprehensive Headache Center, Beth Israel Deaconess Medical Center, Harvard Medical School, Boston, MA, USA. ${ }^{4}$ Department of Neurology, Beth Israel Deaconess Medical Center, Harvard Medical School, Boston, MA, USA. ${ }^{5}$ Department of Anesthesia, Critical Care and Pain Medicine, Beth Israel Deaconess Medical Center, Harvard Medical School, Boston, MA, USA. ${ }^{6}$ Department of Clinical Medicine, Faculty of Health and Medical Sciences, University of Copenhagen, Copenhagen, Denmark. 'Department of Neurology, Albert Einstein College of Medicine, Bronx, NY, USA. ${ }^{8}$ Montefiore Headache Center, Bronx, NY, USA.

Received: 17 May 2021 Accepted: 5 July 2021

Published online: 26 July 2021

\section{References}

1. Nampiaparampil DE (2008) Prevalence of chronic pain after traumatic brain injury: a systematic review. JAMA 300(6):711-719. https://doi.org/10.1001/ja ma.300.6.711

2. Ashina H, Porreca F, Anderson T, Amin FM, Ashina M, Schytz HW, Dodick DW (2019) Post-traumatic headache: epidemiology and pathophysiological insights. Nat Rev Neurol 15(10):607-617. https://doi.org/10.1038/s41582-0190243-8

3. Ashina H, Eigenbrodt AK, Seifert T, Sinclair AJ, Scher Al, Schytz HW, Lee MJ, de Icco R, Finkel AG, Ashina M (2021) Post-traumatic headache attributed to traumatic brain injury: classification, clinical characteristics, and treatment. Lancet Neurol 20(6):460-469. https://doi.org/10.1016/S1474-4422(21)00094-6

4. Couch JR, Lipton RB, Stewart WF, Scher Al (2007) Head or neck injury increases the risk of chronic daily headache: a population-based study. Neurology 69(11):1169-1177. https://doi.org/10.1212/01.wnl.0000276985. 07981.0a

5. Ashina H, Iljazi A, Al-Khazali HM, Ashina S, Jensen RH, Amin FM et al (2020) Persistent post-traumatic headache attributed to mild traumatic brain injury: deep phenotyping and treatment patterns. Cephalalgia 40(6):554-564 https://doi.org/10.1177/0333102420909865

6. Lieba-Samal D, Platzer P, Seidel S, Klaschterka P, Knopf A, Wober C (2011) Characteristics of acute posttraumatic headache following mild head injury. Cephalalgia. 31(16):1618-1626. https://doi.org/10.1177/0333102411428954

7. Minen MT, Boubour A, Walia H, Barr W (2016) Post-concussive syndrome: a focus on post-traumatic headache and related cognitive, psychiatric, and sleep issues. Curr Neurol Neurosci Rep 16(11):100. https://doi.org/10.1007/ s11910-016-0697-7

8. Headache Classification Committee of the International Headache Society (IHS) (2018) The International Classification of Headache Disorders, 3rd edition. Cephalalgia 38(1):1-211

9. Theeler B, Lucas S, Riechers RG 2nd, Ruff RL (2013) Post-traumatic headaches in civilians and military personnel: a comparative, clinical review. Headache 53(6):881-900. https://doi.org/10.1111/head.12123

10. World Medical A (2013) World medical association declaration of Helsinki: ethical principles for medical research involving human subjects. JAMA. 310(20):2191-2194

11. Ashina H, Al-Khazali HM, Iljazi A, Ashina S, Jorgensen NR, Amin FM et al (2020) Low plasma levels of calcitonin gene-related peptide in persistent post-traumatic headache attributed to mild traumatic brain injury. Cephalalgia 40(12):1276-1282. https://doi.org/10.1177/0333102420941115

12. Ashina H, Iljazi A, Al-Khazali HM, Christensen CE, Amin FM, Ashina M et al (2020) Hypersensitivity to Calcitonin Gene-Related Peptide in Post-Traumatic Headache. Ann Neurol 88(6):1220-1228

13. Ashina H, Iljazi A, Amin FM, Ashina M, Lipton RB, Schytz HW (2020) Interrelations between migraine-like headache and persistent post-traumatic headache attributed to mild traumatic brain injury: a prospective diary study. J Headache Pain 21(1):134. https://doi.org/10.1186/s10194-020-012026

14. Buysse DJ, Reynolds CF 3rd, Monk TH, Berman SR, Kupfer DJ (1989) The Pittsburgh sleep quality index: a new instrument for psychiatric practice and research. Psychiatry Res 28(2):193-213. https://doi.org/10.1016/0165-1781 (89) $90047-4$
15. Snaith RP (2003) The hospital anxiety and depression scale. Health Qual Life Outcomes 1(1):29. https://doi.org/10.1186/1477-7525-1-29

16. Nasreddine ZS, Phillips NA, Bedirian V, Charbonneau S, Whitehead V, Collin I et al (2005) The Montreal cognitive assessment, MoCA: a brief screening tool for mild cognitive impairment. J Am Geriatr Soc 53(4):695-699. https:// doi.org/10.1111/j.1532-5415.2005.53221.x

17. Mollica RF, Caspi-Yavin Y, Bollini P, Truong T, Tor S, Lavelle J (1992) The Harvard trauma questionnaire. Validating a cross-cultural instrument for measuring torture, trauma, and posttraumatic stress disorder in Indochinese refugees. J Nerv Ment Dis 180(2):111-116. https://doi.org/10.1097/ 00005053-199202000-00008

18. Kim SK, Chong CD, Dumkrieger G, Ross K, Berisha V, Schwedt TJ (2020) Clinical correlates of insomnia in patients with persistent post-traumatic headache compared with migraine. J Headache Pain 21(1):33. https://doi. org/10.1186/s10194-020-01103-8

19. Buse DC, Reed ML, Fanning KM, Bostic R, Dodick DW, Schwedt TJ, Munjal S, Singh P, Lipton RB (2020) Comorbid and co-occurring conditions in migraine and associated risk of increasing headache pain intensity and headache frequency: results of the migraine in America symptoms and treatment (MAST) study. J Headache Pain 21(1):23. https://doi.org/10.1186/s1 0194-020-1084-y

20. Mathias JL, Alvaro PK (2012) Prevalence of sleep disturbances, disorders, and problems following traumatic brain injury: a meta-analysis. Sleep Med 13(7): 898-905. https://doi.org/10.1016/j.sleep.2012.04.006

21. Scholten AC, Haagsma JA, Cnossen MC, Olff M, van Beeck EF, Polinder S (2016) Prevalence of and risk factors for anxiety and depressive disorders after traumatic brain injury: a systematic review. J Neurotrauma 33(22):19691994. https://doi.org/10.1089/neu.2015.4252

22. Stein MB, Jain S, Giacino JT, Levin H, Dikmen S, Nelson LD, Vassar MJ, Okonkwo DO, Diaz-Arrastia R, Robertson CS, Mukherjee P, McCrea M, Mac Donald CL, Yue JK, Yuh E, Sun X, Campbell-Sills L, Temkin N, Manley GT, and the TRACK-TBI Investigators, Adeoye O, Badjatia N, Boase K, Bodien Y, Bullock MR, Chesnut R, Corrigan JD, Crawford K, Diaz-Arrastia R, Dikmen S, Duhaime AC, Ellenbogen R, Feeser VR, Ferguson A, Foreman B, Gardner R, Gaudette E, Giacino JT, Gonzalez L, Gopinath S, Gullapalli R, Hemphill JC, Hotz G, Jain S, Korley F, Kramer J, Kreitzer N, Levin H, Lindsell C, Machamer J, Madden C, Martin A, McAllister T, McCrea M, Merchant R, Mukherjee P, Nelson LD, Noel F, Okonkwo DO, Palacios E, Perl D, Puccio A, Rabinowitz M, Robertson CS, Rosand J, Sander A, Satris G, Schnyer D, Seabury S, Sherer M, Stein MB, Taylor S, Toga A, Temkin N, Valadka A, Vassar MJ, Vespa P, Wang K, Yue JK, Yuh E, Zafonte R (2019) Risk of posttraumatic stress disorder and major depression in civilian patients after mild traumatic brain injury: a TRACK-TBI study. JAMA Psychiatry 76(3):249-258. https://doi.org/10.1001/ja mapsychiatry.2018.4288

23. Yilmaz $T$, Roks $G$, de Koning $M$, Scheenen $M$, van der Horn $H$, Plas $G$, Hageman G, Schoonman G, Spikman J, van der Naalt J (2017) Risk factors and outcomes associated with post-traumatic headache after mild traumatic brain injury. Emerg Med J 34(12):800-805. https://doi.org/10.1136/ emermed-2015-205429

24. McMahon P, Hricik A, Yue JK, Puccio AM, Inoue T, Lingsma HF et al (2014) Symptomatology and functional outcome in mild traumatic brain injury: results from the prospective TRACK-TBI study. J Neurotrauma 31(1):26-33. https://doi.org/10.1089/neu.2013.2984

25. Frenette LC, Tinawi S, Correa JA, Alturki AY, LeBlanc J, Feyz M et al (2018) Early detection of cognitive impairments with the Montreal cognitive assessment in patients with uncomplicated and complicated mild traumatic brain injury. Brain Inj:1-9

26. Iljazi A, Ashina H, Al-Khazali HM, Lipton RB, Ashina M, Schytz HW et al (2020) Post-traumatic stress disorder after traumatic brain injury-a systematic review and meta-analysis. Neurol Sci 41(10):2737-2746. https://doi.org/10.1 007/s10072-020-04458-7

27. Iljazi A, Ashina H, Al-Khazali HM, Ashina M, Schytz HW, Ashina S (2020) Posttraumatic stress disorder attributed to traumatic brain injury in children - a systematic review. Brain Inj 34(7):857-863. https://doi.org/10.1080/02 699052.2020.1764104

28. Kjeldgaard D, Forchhammer H, Teasdale T, Jensen RH (2014) Chronic posttraumatic headache after mild head injury: a descriptive study. Cephalalgia. 34(3):191-200. https://doi.org/10.1177/0333102413505236

29. Chibnall JT, Duckro PN (1994) Post-traumatic stress disorder in chronic posttraumatic headache patients. Headache. 34(6):357-361. https://doi.org/1 0.1111/j.1526-4610.1994.hed3406357.x 
30. Defrin R, Riabinin M, Feingold Y, Schreiber S, Pick CG (2015) Deficient pain modulatory systems in patients with mild traumatic brain and chronic posttraumatic headache: implications for its mechanism. J Neurotrauma 32(1): 28-37. https://doi.org/10.1089/neu.2014.3359

31. Wang SJ, Chen PK, Fuh JL (2010) Comorbidities of migraine. Front Neurol 1: 16

32. Ashina M, Katsarava Z, Do TP, Buse DC, Pozo-Rosich P, Ozge A et al (2021) Migraine: epidemiology and systems of care. Lancet 397(10283):1485-1495. https://doi.org/10.1016/S0140-6736(20)32160-7

33. Ashina S, Mitsikostas DD, Lee MJ, Yamani N, Wang SJ, Messina R, Ashina H, Buse DC, Pozo-Rosich P, Jensen RH, Diener HC, Lipton RB (2021) Tensiontype headache. Nat Rev Dis Primers 7(1):24. https://doi.org/10.1038/s41572021-00257-2

\section{Publisher's Note}

Springer Nature remains neutral with regard to jurisdictional claims in published maps and institutional affiliations.

Ready to submit your research? Choose BMC and benefit from:

- fast, convenient online submission

- thorough peer review by experienced researchers in your field

- rapid publication on acceptance

- support for research data, including large and complex data types

- gold Open Access which fosters wider collaboration and increased citations

- maximum visibility for your research: over $100 \mathrm{M}$ website views per year

At BMC, research is always in progress.

Learn more biomedcentral.com/submissions 